\title{
Modeling Ecological Security of a State
}

\author{
Natalia Skiter \\ Doctor of Economics, Professor of the Department of Insurance, Financial and Economic Analysis, \\ Volgograd State Agrarian University, Volgograd, Russia \\ Email: ckumep@mail.ru \\ Aleksey F. Rogachev \\ Volgograd State Agricultural University, Volgograd, Russia \\ Email: rafr@mail.ru \\ Tamara I. Mazaeva \\ Volgograd State Agrarian University, Volgograd, Russia
}

\section{Doi:10.5901/mjss.2015.v6n3s6p185}

Abstract

The purpose of the article is to develop a model of ecological security of a state. This purpose can be reached with the help of the following methods: induction, deduction, synthesis, comparative and problem analysis, modeling, and systemic approach. The authors analyze the modern situation in the global economy and determine the reasons for provision of ecological security. The authors consider the currents notions of national security and ecological security and determine the role of economic security in provision of national security of the state. As a result of the research, the authors concluded that the objective situation in modern global economy stipulates the necessity for provision of ecological security. In order to solve a variety of ecological problems, created by anthropogenous influence, the authors developed the model of ecological security of the state, the key instruments of which are ecological marking and ecological taxation. The offered tools of ecological marking and introducing ecological taxes throughout the world will ensure the efficiency of managing the ecological security, as they will form the internal moral motivation of economic agents for support for ecological security and external material stimulation. Implementation of the developed model of ecological security of the state will allow using the market tools of providing ecological security, through forming the demand for ecologically clean products due to the systems of ecological markings and due to mechanisms of state regulation of economy through the tax system, which ensures the complexity and efficiency of the developed model.

Keywords: ecological security of the state, national security, ecological marking, ecological taxation.

\section{Introduction}

Provision of national security is one of the most important functions of the state. Ecological security is one of the most complex problems of national security at the modern stage of development of global economy. The necessity for responsible attitude towards anthroposphere and creation of economic mechanism for prevention of harmful influence, caused to the planet's ecology, are understood by the humanity and written down in the provisions of Kyoto protocol of United Nations Framework Convention on Climate Change.

Deep socio-political changes that happened in the world during recent years also required a new scientifically substantiated model of ecological security of the state, which is at the stage of formation nowadays. It is obvious that this model should view ecological security in an integrated manner and from systemic positions, and represent it as a complex, multilevel, and multilink system. The development and substantiation of such model is the topic of this research.

\section{Research Methods}

At present, there is no single notion of "national security". Some authors understand it as internal and external position of the state at which there is no threat to its national interests (Bondar-Nowakowska and Hachoł, 2014).Other authors put in this notion the protection from external and internal threats, which are various in their nature: political, military, economic, 
intellectual, ecological, etc. (Bucagu et al., 2014). Other authors define national security as state of things in various spheres of state activity at which there is no internal or external threat of emergence of anything dangerous or undesirable, which is able to damage national interests (Changizi et al., 2014). And, at last, some authors consider national security to be the state at which national interests are not threatened by danger and are protected from external and internal threats (Fan et al., 2014).

Despite the difference in definitions, the sense of this notion means the guaranteed provision for citizens of a country of conditions, necessary for civilized life, for improvement and development. The above mentioned shows that there are two types of national security of the state: external and internal, and the very notion of "national security" is based on three main notions: "interest" - "threat" - "protection". In the variety of various types of security, which comprise national security, ecological security has a special place (Haas et al., 2014). This is stipulated by a variety of objective reasons.

Firstly, ecological security is related to protection and use of the most important basis, the origin of human living external environment, which does not have any administrative, national, or state borders. Secondly, solving the problems of ecology and providing ecological security is an important and necessary precondition for solving economic, social, political, and other problems of the state.

Thirdly, ecological crisis can be much more dangerous - as to its scale and consequences - than, for example, political, military, economic, financial, or informational one, and its negotiation can last for decades or even hundreds of years. Fourthly, multidimensionality, complexity, large scale, and depth of ecological problems make ecological security one of the most important items in modern conditions of the development of state.

Analysis of various formulations and definitions of the notion of "ecological security", which are given in the literature and laws used in practice, shows that still there is no single definition reflecting the sense of this notion. Some treat ecological security as a state of protection of human, society, and environment from harmful influences of anthropogenous factors, natural hazards, and catastrophes (Taylor, 2014). Others define ecological security as a component of environmental protection (Xie, 2014). Still others equate ecological security and environment protection (Bucagu et al., 2014). Still others use the notion of "ecological security" to denote not only environment protection but also rational use of natural resources, their reproduction, and quality improvement (Yin et al., 2014).

According to the authors if this research, none of the viewed formulations of ecological security cannot be accepted as a basic notion, as none of it neither reflects the sense of ecological security, not contains its basics, like ecological interests, ecological threats, and ecological protection. From the positions of complex systemic approach, ecological security is appropriate to be viewed from several aspects. Firstly, as one of the main components of national security of the state, i.e., as a sublevel of a higher system, which is national security.

Secondly, as an independent separate type of security, which includes other types of security of lesser level, i.e., as an independent complex multilevel system which has its own subsystems (components of lesser level). And, finally, as a complex attribute of any product of social labor, for example, building, industrial, or energy object, technology of various type and purpose, utility products, food, etc. As to the products of social labor (the last aspect), ecological security can be understood as ecological cleanliness.

It is obvious that ecological security - like national security - can be external or internal, and it is based in three main notions: "ecological interests", "ecological threat", and "ecological protection". Ecological interests are objective needs of society for living in harmony with nature, breathing clean air, drinking clean water, consuming clean food, and using the natural resources of our country in a rational way.

Ecological interests are, of course, very important and long-term. The sense of all ecological interests is eventually brought down to preservation of natural habitat in the process of industrial, military, or other activity of human, society, or state for the purpose of physical survival of our society, its efficiency in face of ecological threats, as well as during natural and anthropogenous catastrophes and natural disasters. Preservation of natural habitat, in its turn, is possible by means of sustaining the acceptable limits of quantitative and qualitative indicators of natural and artificial habitat, as well as preservation and rational use of natural resources.

Nowadays, the ecological interests of our state include recovery of natural ecological systems of human life and activities (atmosphere, water, earth, and space), implementation and use of non-waste high efficiency technologies, destruction of ecologically dangerous waste, etc. Ecological threat for Russia's security has internal and external sources die to the influence of anthropogenic (human) factors, i.e., ill-considered and destructive use of natural resources and implementation of technologies which are really or potentially dangerous for natural environment and human (Skiter, Rogachev, Shokhnekh, 2014).

Besides, nowadays, ecological threat also comes from consequences of natural processes and phenomena, demographic pressure of the population on limited resources of the country, depletion of natural resources, poisoning or 
destruction of the systems of human life and activities, of animal and plant world, accumulation of radioactive, poisonous, explosive, and similar technologies and weapons. Recently, a particular threat for ecological security of Russia comes from society's loss of interest to ecological problems and indifference of the most of the Russians to the state of natural environment.

Ecological threats can be divided into real and potential.

Ecological protection includes, primarily, measures of nature protection, aimed at the provision of ecological security. It is obvious that nature protection measures, related to prevention of threats to ecological interests, should be included to passive protection or passive provision of ecological security. At the same time, the measures, aimed at limiting and eliminating the consequences of ecological threat, can be called ecological protection or active provision of ecological security.

Nowadays, passive ecological protection includes development of ecological laws and requirements for provision of ecological security, control of environment, building projects for environment and nature protection systems and construction, ecological education and training, ecological agitation and propaganda, ecological certification, monitoring, etc.

Active provision of ecological security, in its turn, includes practical realization of laws and requirements, implementation and use of nature protection construction and non-waste technologies, actions for prevention of ecological threats, natural disasters, and catastrophes.

The authors of this research offer their own formulation of the basic nation of "ecological security", which, being the fullest one, objectively reflects the sense and basic ideas of these components of national security.

Ecological security is:

1. Component (part) of national security of a state.

2. State or position at which there are no real or potential threats for ecological interests of a person, society, or state, which emerge due to violation of natural balance, aggravation of environment's quality, destruction of natural resources, destruction of natural ecological systems, and other negative consequences, caused by anthropogenic influence on the environment, as by natural processes and phenomena.

3. A complex attribute of any product of social labor, which is manifested at all stages of its life cycle and consists in ability not to violate the qualities of external (natural or anthropogenic) environment and not to create a threat for life or existence of people, flora, and fauna. In respect to the products of social labor, ecological security may be identified with ecological cleanliness of a product.

The above mentioned definition of ecological security implies that primarily it is necessary to protect the natural environment, its elements (components), and ecosystems from anthropogenic activity of human. At the same time, human, society, and state should be protected from catastrophes, disasters, and situations, caused both by natural and anthropogenic reasons.

The authors of this research consider that at present, ecological security includes not less than 15 interconnected subsystems (types), which are its components. The subsystems of ecological security are the following:

1. Electrical security

2. Mechanical security

3. Electromagnetic security

4. Heat security

5. Nuclear security

6. Radiation security

7. Chemical security

8. Protection from radioactive items, toxins, biological weapon

9. Vibronoise security

10. Toxicological security

11. Light security

12. Fire and explosion security

13. Atmosphere pollution protection

14. Water contamination protection

15. Territories and lands contamination protection

Analysis of the components of ecological security shows that with regard to natural ecological systems (for example, atmosphere, earth, water, space), ecological security is brought down to ecological protection. In this case, ecological security should be understood as the state of protection of earth and water from anthropogenic activity of human, society, and state from nature processes and phenomena. 
The main condition of successful solution of ecological problems, according to the authors, is the level of scientific and technical provision of ecological security in certain spheres (industry, agriculture, energetics, etc.) and in the state as a whole (Rogachev, Skiter, 2014). As the main influence on the natural environment is done by artificially created (anthropogenic) objects and anthropogenic activity of human, a special role in the system of provision of ecological interests, prevention of ecological threats, and implementation of measures of ecological protection belongs to scientifically developed system of ecological security, which is intended to solve and forecast the possible ecological problems.

It should be noted that as of today, the global economy has approx. $15 \%$ of the polluted territories, where the ecological problems are especially keen, natural resources are depleted, and ecological situation is close to a crisis. It is a known fact that today, the economic damage from pollution of environment in the Russian Federation constitutes about half of the national treasure of the country.

It is becoming apparent that it is high time to provide ecological security and take the center of gravity of ecological security from passive measures to active ones, which supposes the following:

- creating the data base of nature protection, resource-saving, and ecologically clean technologies;

- searching for scientists, engineers, and specialists, and creating mobile scientific societies, which are capable to develop and implement the leading, high efficiency technologies of ecological purpose, ensuring material, technical, and financial provision of scientific developments as to providing ecological security;

- charging the state nature protection authorities with duties of practical elimination of the revealed ecological violations.

Nevertheless, the existing ecological problems have to be solved indirectly, restoring the quality of natural environment, or indirectly, through support and restoration of the population's health.

\section{Results}

For the global society, the entry into 2000s meant the strengthening of anthropogenic, mostly human, pressure on the environment. The necessity for understanding of the current situation puts the ecological problematics into the foreground of the hierarchy of the modern global problems. It is becoming more and more apparent that humanity has to choose the ecologically oriented social development, at which the economic growth should be measured not only in quantity but in quality, which will finally be transformed into quantitative type. Thus, according to United Nations Environmental Program, the unpolluted environment raises the labor efficiency by $10-15 \%$, and industrial costs reduce by $60 \%$ (Popkova and Tinyakova, 2013a).

Consequently, this research offers a proprietary model of ecological security of the state. Within the offered model of ecological security of the state, the authors suggest the ecological marking of products, which today is one of the instruments of ecological policy in the global practice and is oriented at the development of the market and aimed at the encouragement of developing products with enhanced ecological parameters, which facilitates the improvement of ecological security of the society.

Ecological marking is a procedure of ascribing the ecological sign for products which possess certain ecological advantages over the analogues within a certain group of homogeneous products. Ecological marking is voluntary and can be used by public or private agencies. The tasks of ecological industrial policy consist in differentiation of existing products from the point of view of ecological acceptability, in changing or refusing the "harmful" products, innovations, or their components by means of refocusing the industrial process at the requirements that conform to the aims of environment protection.

The process of manufacture of products should take into account that top quality products are possess the following levels of ecological quality:

1) high quality of main utility of a product - acceptability of consumption, durability, capability for maintenance, nutrition value, taste, external view;

2) ecological quality of a product as a whole - absence of harmful agents; its usage or consumption does not lead to emergence of remaining materials, and the conditions of exploitation do not have negative influence on the environment;

3) ecological quality of production - minimization of usage of materials and energy, substitution of deficit raw materials and energy for raw materials and energy which are in good supply, reduction of emissions (spew) and waste of all types;

4) ecological quality of waste elimination - use of products suitable for recycling (secondary use) due to refusal 
from conjugated materials, which are problematic from the position of their recycling, or due to use of materials for which there is a ready system of recycling.

Evaluation of ecological compatibility of products includes determining the level of its influence on the environment during the whole life cycle of a product: from extraction of raw materials for production to the final utilization. The main goal of ecological marking is to allocate among the group of homogeneous products the one that has the least influence on the environment at all stages of its life cycle. Ultimately, the purpose of the measures for assigning ecological marking is to organize the competition between groups of products which inflict damage to the environment.

Ecological marking is one of the types of ecological declaration. Marking can have a form of a sign, graphic image, or may be represented in a form of text document, technical bulletin, or public advertisement. The standards forbid using ecological marking with unclear and obscure formulations, such as "ecologically safe", "ecologically favorable", "favorable for soil", "non-polluting", "green", "favorable for nature", etc.

Ecological mark is assigned for the period of three years. After this time, the criteria are reconsidered, taking into account the development of new technologies, emergence of new product with similar functions (but lesser influence on the environment) and new information about the state of the environment or change of market conditions. Ecological mark may be assigned only to the products which cause less negative ecological influence in comparison with other products that perform the same functions.

According to the international standard ISO 14020, there are three types of ecological markings: 1 ) mark which is assigned as a result of certification of product by a third party; 2) mark which is based on self-declaration: a manufacturer can mark its production with a special sign; 3) mark which is similar to the first type of mark, but connected to certain qualitative information as to characteristics of ecological compatibility at the stages of product's life cycle.

According to the principles of ecological marking, ecological marks and declarations should be specific, ascertainable, appropriate, and explicit. Information on nature of ecological compatibility of products and services in the declaration is provided to a consumer by the manufacturer. Ecological marking and declaration are based on the scientific methodology, which includes the consideration of the life cycle of a product, evaluation of ecological risk, and provision of reproduction of test results. Ecological marking's information should be available for interested parties, its procedures and criteria should not create additional barriers in trade or discrimination in purchase of domestic or foreign products and services.

The programs of ecological marking include: list of groups of homogeneous products which have a right for marking; criteria for ecological cleanliness; functional characteristic of products; order of certification of products; requirements of periodic revision of programs; sources of financing of the ecological marking programs; methods for testing and verifying the results; periodic check of product's conforming to the criteria.

A product may be deprived the ecological mark if manufacturer provided false information about ecological parameters of his product, misused his authorities as to assigning the mark, if ecological quality of product ceased to conform to the criteria of ecological cleanliness or there arose new, previously unknown information as to harmful influence of a product on the environment.

Ecological marks may be conventionally divided into three main groups.

1. Marks which denote safety for environment from the products in a whole or their components. They may be used for marking products and appliances used for nature protection and as ecological symbols. The most famous among these are German "Blue angel", "White swan" (Scandinavian countries), Japanese "Eco-mark", and others (all signs are represented on the inner side of the back of the journal cover).

2. Marks and inscriptions, calling for environment protection, and marks denoting products that can be recycled or that were produced as a result of recycling. There are many of them, but the most popular are those that present the closed cycle, denoting the system "creation-use-utilization" with indication of material, of which the product is made. According to the requirements of the EU Directive, every package should be marked with the following signs (picture on the cover):

- recycling or multiple use;

- recycling ("Mobius strip");

- partly or fully produced of recycled materials with indication of its percentage composition.

If required, for identification of material of package and easy sorting, it is marked with numbers or letters which are usually situated in the center (sometimes beneath) of the sign, allowing determining the material type.

1. Marks, calling for environment protection, which are usually seen on the package of consumer goods. They appeal not to litter, keep clean, and give the used goods for recycling, putting them into the corresponding trash cans (см. puc.).

2. Marks, warning of the danger of a product for the environment. For example, for marking stuff which is 
hazardous for marine flora and fauna at its transportation by sea. They include the mark "Environmentally hostile" (used by the EU law).

Certification of products as to its conforming to the international ecological standards acquires more significance in the global economy. The export from the countries that perform an effective ecological policy has a tendency for a quick growth. The global market of ecologically clean market is actively developing. In 2013, its volume constituted USD 25 billion. Annual growth rates in the developed countries consist 20-30\%. Thus, in 2012, the sale of ecologically clean products in the USA constituted USD 11.7 billion, or 1.8\% of the total volume of the food market. Ecologically clean food, being supported by public opinion and the state, has been developing since 1970 as an antipode of fast food and now attracts a huge flow of buyers (approx. $25 \%$ of the US population consume ecologically clean products), having successfully finished the transition from small private stores to the network of specialized supermarkets (Popkova and Tinyakova, 2013b).

Governments of the developed countries actively support the eco-production, as it facilitates the strengthening of internal market and growth of export, this helping to solve economic and ecological problems. At present, 32 countries of the world have the standards of ecologically clean products, 9 countries are in the process of implementing them, and 15 countries are developing these standards.

As a second instrument of the model of ecological security of the state, this research suggests the rate for using natural resources. The state regulation of ecological security and its financial provision supposes the development of civilized tax relations taking into account the international obligations and the society's interest in stimulating eco-saving technologies and strengthening tax pressure on "polluting" productions.

Under conditions of economic crisis, the search for additional sources of budget revenue and efficiency of spending the accumulated financial resources on ecological purposes, the necessity for distribution of tax pressure, and improvement of the procedures of administrating the sphere of natural resources seem to be very topical.

Generalization of global experience of taxation in ecological sphere allows offering the following directions of its improvement in the Russian Federation, the topicality of which is predetermined by the task of searching for additional sources of budget revenue under conditions of economic crisis and the necessity for redistribution of tax pressure. In particular, it is advisable to implement the following types of ecological taxes.

1. Tax on products, the manufacture of which is accompanied by negative ecological externalities, or "product" tax. This tax may be understood as the tax on usage of ecologically harmful technologies of production. Entrepreneurs that are planning to use ecologically safe technologies should receive tax advantages. The product tax is an indirect tax, as it stimulates the rise of market price of corresponding products, which leads to limitation and rationalization of their consumption. Thus, ecologically harmful, but cheap at production, products will be more expensive that ecologically safe. The product tax may be used for disposable containers, various containers for liquids (if they are not under the deposit system), aluminum foil, pesticides, certain detergents, salt for roads, etc. The object of taxation may be the products which are made of deficit raw materials, for example, tropical timber.

2. Tax for consumption of products which are harmful for the environment. These may include taxes for various types of fuel, e.g., gas - depending on the lead content - and taxes on carbon content in fuel (Skiter, 2011). For example, in Germany this tax is included in the price of gas. That's why the Germans try to use cars which consume less gas and, correspondingly, pollute the environment not so much, which creates the regulating effect of the tax for the environment protection. In some countries, the tax obligation is reduced substantially for cars with low content of hazardous substances in exhaust. In some countries, the tax grows with fuel consumption. This stimulates to buy fuel-efficient and environment-friendly cars. The object of ecological taxation may be cars which are more than 10 years old at the moment of registration. In respect to motor transport, ecological taxes are divided into 4 groups: tax paid during the purchase of a car or during start of its exploitation (registration fee); annual transport tax; taxes on fuel; other taxes and fees (insurance, toll roads, parking, etc.).

Special registration fees on motor transport also have an ecological purpose; the level of the fees depends on fuel consumption according to fuel standards. Regardless of the fact that the order of payment, consequences of nonpayment, and other aspects of regulation are different for taxes and fees (a lot of aspects, applicable to taxes (taxpayer, tax agent, taxation object), are not applicable to fees), registration fees possess the main characteristics of a tax with special peculiarity of their calculation and payment. Registration fee is paid in 10 countries of the EU. This fee usually depends on the price of a car, engine power, fuel consumption, exhaust norms, or combination of these factors. The simplest scheme of the fee calculation is in Denmark - proportionally with a price. In Austria, the fee depends on the fuel consumption. With regard to Russia, there may be the introduction of ecological fee from the motor vehicles (non- 
residents) entering the country.

1. Custom taxes on the import of ecologically harmful products.

2. Tax on recycling or "deposit value". It is about a fixed addition to the product price, taking into account the costs of recycling of a product after its use. Thanks to this tax, it is very profitable to recycle plastic bottles, tires, and other stuff in Canada. At that, the consumer of a product is not affected. Giving away the waste to the drop-off station, he gets the deposit value back.

The main advantage of these taxes is effective (without using administrative measures) forcing out from the market the undesirable, i.e., harmful products and creation of competitive advantage for products with better ecological parameters. Besides, introduction of additional taxes will allow receiving additional funds for the purpose of general budget incomes, which are limited due to negative crisis situation in the economy, and for realization of the state policy in the sphere of environment protection. At that, the implementation of new ecological taxes should be accompanied by control for the constancy of general tax load.

Financial resources, which are formed on the basis of arrival of ecological taxes into the budget, should be directed to the stimulation of the environment protection by consumers, development and implementation of non-waste technologies, utilization of waste, cleaning old junkyards, etc. Thus, in Denmark there is a special scheme, based on these funds - it gathers old and out-of-use cars. According to this scheme, owners of transport vehicles, the use of which is connected with substantial load on the environment (these are cars that are more than 10 years old), receive a special bonus for their "gathering".

The funds accumulated from the ecological taxes and fees are advised to distribute in the following way: $10 \%-$ federal ecological fund, $30 \%$ - ecological funds of the regions, $60 \%$ - local ecological funds. At that, the administrators of the accumulated funds should be the tax authorities. The offered directions of improvement of taxation system in the sphere of environment protection and natural resource use will allow, on the one hand, regulating the public relations in the direction of realization of ecological security policy, and, on the other hand, providing the formation of necessary funds for nature protection purposes.

\section{Conclusions}

It may be concluded that ecological security is one of the main elements in the system of national security, as it refers to the source of life - human environment. Ecological security is an independent, complex, and special type in the system of national security of Russia, which does not have national, administrative, or state borders. The basis of ecological security is ecological interests, ecological threat, and ecological protection. It is impossible to increase the level of provision of ecological security under modern conditions without perfect ecological legislation, involvement of variety of scientists, engineers, and specialists, and implementation of technical means and methods of active ecological protection.

The offered tools of ecological marking and implementation of ecological taxes throughout the world will provide the efficiency of managing the ecological security, as they will form the internal moral motivation of economic agents for support for ecological security and external material stimulation. Implementing the developed model of ecological security of the state will allow using market mechanisms of provision of ecological security through forming the demand for ecologically clean products through the systems of ecological markings, and using the mechanisms of state regulation of the economy through taxation system, which ensures the complexity and efficiency of the developed model.

\section{Acknowledgements}

This article was prepared with financial support of Russian Foundation for Basic Research and Administration of Volgograd Oblast for the project "Mathematical modeling and improving the institute of tax mechanisms for provision of ecological security of Volgograd region in view of intersectorial externalities" No. 15-46-02566 p_Povolzhye_a

\section{References}

Bondar-Nowakowska, E., Hachoł, J. (2014). The risk as a measure of ecological safety in watercourses. Journal of Water and Land Development, 20(1), 3-10.

Bucagu, C., Vanlauwe, B., Van Wijk, M.T.,Giller, K.E. (2014). Resource use and food self-sufficiency at farm scale within two agroecological zones of Rwanda. Food Security, 6(5), 609-628.

Changizi, M.A., Brucksch, M., Kotecha, R.,McDonald, K., Rio, K. (2014). Ecological warnings. Safety Science, 61, 36-42. 
Fan, J.X., Wen, M., Kowaleski-Jones, L. (2014). An ecological analysis of environmental correlates of active commuting in urban U.S. Health and Place, 30, 242-250.

Haas, E.J., Hoebbel, C.L., Rost, K.A. (2014). An analysis of trainers' perspectives within an ecological framework: Factors that influence mine safety training processes. Safety and Health at Work, 5 (3), 118-124.

Popkova E.G., Tinyakova V.I. New Quality of Economic Growth at the Present Stage of Development of the World Economy. World Applied Sciences Journal. 2013a, 24(5): 617622.

Popkova E.G., Tinyakova V.I. Drivers and Contradictions of Formation of New Quality of Economic Growth. Middle-East Journal of Scientific Research. 2013b, 15(11): 16351640.

Rogachev A.F., Skiter N.N. On the question of the ecological security of the region. The world of science, culture and education. - 2014. - №1 (44). - P. 404-407.

Skiter N.N., Rogachev A.F., Šohneh. A. Improvement of tax incentives in the system of environmental safety. Audit and financial analysis. -2014. -No 6.-p. 12-16.

Skiter N.N. Modeling of optimal tax payments for industrial emissions. Business. Education. The right. Bulletin of the Volgograd Institute of business. -2011. - № 1. -P. 201-208.

Taylor, G. (2014). Viability: A priority criterion for the mitigation of climate change and other complex socio-ecological issues. Journal of Futures Studies, 19(1), 77-96.

Xie, Y. (2014). Hotspots of ecological and environmental risk research in China based on co-word analysis. Journal of Information and Computational Science, 11(4), 1185-1192.

Yin, S.-J., Xu, P.-P., Chen, M., Wu, L.-H. (2014). Consumer's preference on value attributes of ecological food and affecting factors. China Population Resources and Environment, 24(4), 71-76. 